\title{
Statistics don't support cot-death murder theory
}

\section{Misunderstanding of statistics is widespread and has led to miscarriages of justice.}

Sir - Your News story "Quashed convictions reignite row over British cot deaths" (Nature 427, 384; 2004) notes concern over the testimony of an expert witness, the distinguished paediatrician Roy Meadow, in several UK court cases in which parents were convicted of murdering their children.

Another aspect of his testimony that should be discussed more widely is the use of statistical arguments to conclude that the probability of two children in the same family dying a cot death was 1 in 73 million. Meadow based this testimony on statistics given in a government-commissioned report. The ' 1 in 73 million' statistic was not the sole basis for Meadow's expert testimony, but sadly, neither the defence nor anybody else in court challenged the simple assumption behind the calculation that two cot deaths in the same family are unlikely to be related in any way.

A more convincing analysis by Ray Hill, a mathematician at Salford University, UK, reveals that, if there has already been one cot death in a family, the chance of a second one is 10 to 22 times higher. See http://pass.maths.org.uk/issue21/features/ clark, where Helen Joyce uses Bayes' theorem to calculate the probability that the deaths arose from natural causes, by using plausible values for the alternative hypothesis that they were murdered. This analysis, which does not require an understanding of the underlying causes of cot death or child murder, leads to a probability of 0.625 that the deaths were natural (see B. Lewis, Math. Gaz. 87, 418-431; 2003).

Unhappily, the understanding that statistics is a difficult subject is not widespread, even among distinguished paediatricians.

Hermann Bondi

Churchill College, Cambridge CB3 ODS, UK

\section{Dangers of crying wolf over risk of extinctions}

Sir-Media coverage of conservation research is usually welcomed by the scientists involved, but there are pitfalls to heed. Damaging simplifications of research findings may expose conservationists to accusations of crying wolf, and play directly into the hands of anti-environmentalists. For example, in January 2004 it was widely reported in the UK print media that one million species would go extinct by 2050 . The original report (Nature 427, 145-148; 2004), however, was based on 1,103 species and clearly stated that - as a consequence of climate change over the next 50 years a variable proportion of land animals and plants might eventually go extinct.

We reviewed 29 reports in the local and national UK press, and found that many of the errors could be traced back to the press releases and agency newswires. In a press release from the lead author's university, the figure of a million species appears along with the claim that a quarter of all land animals and plants may go extinct — but eventually, not by 2050 . Newswires ranged from the cautious ("Hundreds of species of land plants and animals around the globe could vanish or be on the road to extinction over the next 50 years if global warming continues" - Dow Jones International) to the sensational ("Global warming could wipe out a quarter of all species of plants and animals on earth by 2050" - Reuters).

Unsurprisingly, subsequent newspaper articles in the national and local press were highly inaccurate: 21 of the 29 reports we reviewed claimed that a million or more species would be extinct by 2050 . Two reports even claimed that one-third of the entire world's species would become extinct. No reports specified the full range of uncertainty $(5.6 \%$ to $78.6 \%$ of the species studied would be committed to future extinction) and only two correctly stated that most species would become extinct well after 2050 (full details of our survey can be seen at www.geog.ox.ac.uk/ research/biodiversity/pubs/index.html).

Politicians and conservationists repeated these statements. The European Union's environment commissioner Margot Wallström, for example, commented on "the recently published study that suggests global warming could wipe out a third of the planet's species by 2050".

How can the conservation community prevent a repeat of such wide-scale media misrepresentation? Practical steps might be for high-profile journals to restrict press releases in the climate-change arena to research papers that present clear and unequivocal findings, and for scientists to write to newspaper editors and politicians to clarify misleading media articles. More generally, any institute, journal or individual involved in putting out a press release has a responsibility to ensure that it is both accurate and perfectly clear.

Richard J. Ladle, Paul Jepson, Miguel B. Araújo, Robert J. Whittaker

Biodiversity Research Group, School of Geography \& the Environment, Oxford University, Mansfield Road, Oxford OX1 3PS, UK

\section{Error message}

Sir - In the 19 February 2004 issue of Nature, there were ten items (one Brief Communication, one Article and eight Letters to Nature) containing figures with error bars, but only three had figure legends describing what the error bars were: in one case, $80 \%$ confidence intervals; in another, standard deviations; and in the third, standard error of the mean. The articles with incomplete legends represented both the biological and physical sciences, across many different disciplines, and clearly should not be considered isolated examples.

Error bars can be used by the reader to determine how much the data varied, allowing an estimation of whether the experiments gave reproducible results, whether the results were significantly different from the controls, and sometimes whether the data were obtained in an unbiased manner.

How did these omissions occur? If authors include error bars on their figures, why do they so often forget to state what they are in the legends? How can reviewers be confident that the conclusions are correct if they are not told about the errors in the data? Why don't reviewers request that descriptions of the error bars be included when they review the papers?

When properly described, error bars can be very revealing. In their analysis of the experiments and methods used by Jacques Benveniste to study homeopathy, John Maddox and colleagues illustrated how much information can be gained if one knows how to interpret errors correctly (Nature 334, 287-290; 1988).

By not ensuring that all papers that have error bars describe what they are, Nature publishes material that cannot be properly assessed by its readers.

\section{David L. Vaux}

The Walter and Eliza Hall Institute, 1 G Royal Parade, Parkville, Victoria 3050, Australia

Nature is fortunate in having such attentive readers. Our editors and reviewers expect error bars to be properly defined, and we shall be more vigilant in ensuring best practice in future - Editor, Nature. 